\title{
In Vitro Anticancer and Antibacterial Activity of Green Synthesized ZnO NPs Using Clitorea Ternatea Flower Extract: Inhibits MCF-7 Cell Proliferation Via Intrinsic Apoptotic Pathway
}

Mohammed Issa Alahmdi

University of Tabuk

Khasim Syed ( $\nabla$ syed.pes@gmail.com )

University of Tabouk Faculty of Science

Sekar Vanaraj

Jiangsu University

Chellasamy Panneerselvam

University of Tabuk

Mahmoud A Abdelaziz Mahmoud

University of Tabuk

Sayeed Mukhtar

University of Tabuk

Meshari A Alsharif

Umm Al-Qura University

Nahla S Zidan

Tabuk University Saudi Arabia

Nader Elmaghwry Abo-Dya

University of Tabuk

Obaid F Aldosari

Zagazig University

\section{Research Article}

Keywords: Clitorea ternatea, green synthesis, anticancer, MCF-7 cell line, antibacterial activity

Posted Date: January 20th, 2022

DOI: https://doi.org/10.21203/rs.3.rs-1269775/v1

License: (9) This work is licensed under a Creative Commons Attribution 4.0 International License.

Read Full License 
Page $2 / 21$ 


\section{Abstract}

Herein, we report a strategy to synthesize zinc oxide nanoparticles (ZnO NPs) from Clitorea ternatea flower extract through green synthesis platform. The bioactive components in the $C$. ternatea flower extract acts as a stabilizing and capping agent, which enables the synthesis of ZnO NPs without the use of chemical reagents. Synthesis of of ZnO NPs through green platform was confirmed by analytical characterization techniques such as UV-Vis spectrophotometry, XRD, FTIR, DLS, Zeta potential, TEM, and EDX methods. The surface morphology and average size of ZnO NPs investigated through TEM and DLS results indicates rod shaped structure with average particle size of $84 \mathrm{~nm}$. Green synthesized ZnO NPs shows excellent antibacterial, antibiofilm, and antioxidant activity which is dose-dependent. These ZnO NPs have cytotoxicity against breast cancer cells (MCF-7). The MTT test revealed a concentrationdependent inhibitory effect on MCF-7 cells, with IC50 being $12.1 \mathrm{~g} / \mathrm{ml}$, and their anticancer potential was detected utilizing live and dead cell assays $\mathrm{LDH}$ release, $\mathrm{Ao} / \mathrm{EtBr}$ ), DAPI, ROS, and caspase-3 activation assays. Finally, the findings of these results shows that ZnO NPs derived from Clitorea ternatea flower extract are highly potential candidates to treat bacterial infection and human breast cancer.

\section{Introduction}

Nano-biotechnology is a cutting-edge tool in the area of biological activities that promotes the development of nanoscale materials and broad range of applications in the health and medicine sectors [1]. The high reactivity of nanoparticles, along with their physiological, optical, and structural characteristics, make them useful for a variety of applications including clinical research, food processing environmental remediation, automobiles, waste water treatment, and energy storage $[2,3,4]$. Metal oxide nanoparticles are more potential than other nanoparticles [5]. Over the last few decades, numerous chemical, physical, and biological synthesis routes have been implemented [6]. Generally, the chemical, physical methods involved high temperature various toxic chemical and large space and more expensive. As well as utilization of toxic chemical for reduction and capping agent in the nanoparticle production process causes a variety of negative impacts to human health and unfriendly to environment $[7,8]$. Biological nanoparticle production has shown to be safe, nontoxic, low in cost, and good for the environment [9]. There are numerous biological sources used in biological nanomaterials synthesis including plants, microbes, algae etc [10]. Furthermore, the nanoparticles syntheses by plants are more effective, free from hazards, cost less, faster rate of synthesis, and produce different shape and size compared to microbes $[11,12]$.

Currently, there are several metal oxide nanoparticles synthesized by green approach such as Ag [13], Au [14], $\mathrm{CuO}$ [15], $\mathrm{Fe}_{3} \mathrm{O}_{4}$ [16], $\mathrm{NiO} 2$ [17], $\mathrm{TiO}_{2}$ [18] and $\mathrm{ZnO}$ [19]. These green synthesized nanoparticles have potent antibacterial, antioxidant and anticancer activities reported by earlier studies [20]. Among the metal oxide, $\mathrm{ZnO}$ nanoparticles owe distinctive physical and chemical features, which include higher stability, higher exciton binding energy, wide band gap, high optical transmittance and electrochemical coupling coefficient [21, 22]. Plant-based ZnO NP synthesis is a straight forward, low-cost, eco-friendly approach that does not require any intermediate base groups [23]. Plant extracts typically includes divers 
of chemical compounds like alkaloids, tannins, phenol, flavonoids, and terpenoids that can aid in the synthesis of nanoparticles by acting both as reducing and capping agent [24, 25]. Furthermore, phyto fabrication of ZnO-NPs have been used as cosmetics with promising biomedical applications like as drug delivery, antibacterial, anticancer, and mellitus therapies, tissue repair, anti-inflammation, and biomedical imaging etc, $[26,27,28]$. The green synthesized ZnO NPs have inherent antibacterial and anticancer properties due to a variety of mechanisms, including the release of $\mathrm{Zn}$ ions or the formation of ROS after the ZnO NPs are taken up by cancer cells or bacteria, which results in the deregulation of important cellular mechanisms, resulting in increased cellular membrane damage and death [29, 30, 31]. As mentioned in the earlier report, phyto fabrication of ZnO NPs using different plant extracts has been proven to be effective for antibacterial, antioxidant, and anticancer purposes. [32].

Around 7.6 million people die every year from cancer, making it one of the leading causes of death in the world. It is expected that by 2030 , the number of deaths will have risen to 11 million. According to WHO data, cancer killed total of 9.6 million people in 2018, accounting for one out of every six fatalities. [33]. The most frequent cancer treatment and management methods such as chemotherapy, radiation therapy, surgery, and hormone therapy, but the patients suffer from severe side effects and induced strains as a result of the aforementioned treatment techniques. [34,35]. Recently, nano-biotechnology based therapeutic and diagnostic techniques have showed promise to improving cancer treatment in recent years. As a result, the current study aimed to synthesize ZnO NPs in an easy and environmentally friendly manner using $\mathrm{C}$. ternatea $\mathrm{L}$ flower extract.

C.ternatea L., commonly known as Asian Pigeon Wing, is a perennial twinning medicinal plant that has been mostly used in traditional and Ayurvedic medicine systems throughout the world [36]. Some plant chemicals like phenols, Flavanoids, Tannins, Alkaloids, Terpinoids, Cardiac Glycosides, and Steroids found in $\mathrm{C}$. ternatea $\mathrm{L}$ plant flower extract that serve as capping and reducing agents for metal oxide NPs. $[37,38]$. In our understanding, very few reports have been reported to fabrication of ZnO NPs from C. ternatea $L$ using green chemistry, and their antibacterial activity, antioxidant activity, and anticancer activity, but they have not been extensively explored.

The current article intended to explore the synthesis and characterization of Zinc nanoparticles from C. ternatea L flower extract. XRD, TEM, EDX, DLS, Zeta potential and FTIR were used to assess the physicochemical properties of the produced nanomaterials. Antibacterial and antibiofilm properties of ZnONPs tested towards Escherichia coli (E. coli) and Staphylococcus aureus, as well as antioxidant potential employing DPPH radicals. In addition, anticancer efficacy of phyto-synthesized ZnO NPs was examined against breast cancer cell line (MCF-7), and its intrinsic apoptotic pathway was disclosed utilizing several mechanistic tests.

\section{Materials And Methods}

All the chemicals and reagents were procured from Merck-India. Hi-Media provided acridine orange/ethidium bromide, nutrient agar and broth, Mueller-Hinton broth, Luria bertani broth, Crystal violet 
DAPI or 4',6-diamidino-2-phenylindole, and glass wares. MTT Assay Kit (ab211091) was procured from Sigma Aldrich-India. NCCS (National Centre for Cell Sciences) in Pune, India provided the MCF-7 cancer cell line. MDR Clinical pathogens were kept at Bharathiar University's Biopharmaceutical Laboratory, Coimbatore, India.

\subsection{Preparation of flower extract}

Clitorea ternatea was collected from the Rajapalayam, Virudhunagar(district), Tamilnadu, India. The plant sample was submitted in Botanical Survey of India, Coimbatore, India, with proper identification. To prepare the Clitorea ternatea extracts, $10 \mathrm{~g}$ of dried flowers were suspended in $200 \mathrm{ml}$ of $\mathrm{ddH}_{2} \mathrm{O}$, followed by sonication for 1 hour, and then prepared flower extract was kept in the dark for 2 days before being filtered via Whatman Filter paper and stored at $4^{\circ} \mathrm{C}$.

\subsection{Zinc Oxide Nanoparticles from clitorea ternatea flower Extract}

With slight modifications, Clitorea ternatea flower extract synthesized $\mathrm{ZnO}$ nanoparticles using the aforementioned procedure [39]. The solution was prepared by dissolving $0.1 \mathrm{M}$ of $\mathrm{Zn}\left(\mathrm{NO}_{3}\right)_{2} \cdot 6 \mathrm{H}_{2} \mathrm{O}$ in 50 $\mathrm{ml}$ of $\mathrm{dd}_{2} \mathrm{O}$, then adding drop wise $10 \mathrm{ml}$ of Clitorea ternatea flower extract under stirring conditions at $80^{\circ} \mathrm{C}$ for around 4 hours. After stirring, the complex mixture goes to centrifugation at $12,000 \mathrm{rpm}$ for 10 minutes to recover it. The obtained complex materials cleaned with distilled water and separated by centrifugation. After cleaning, the complex materials kept in an oven at $40^{\circ} \mathrm{C}$ for 8 hours for drying.

\subsection{Characterization of green synthesized ZnO NPs}

Green synthesized Zno NPs were characterized by UV-Spectrophotometer (Shimadzu Uv-2500). The crystalline phase and purity of the materials were analyzed with the help of Rigaku, X-ray Diffractometer, ranging between $20^{\circ}$ to $80^{\circ}$. The morphological studies were carried out by Zeiss-EM10C TEM. We have also used EDS zeta potential and DLS to analyze their elemental mapping, stability and particle size using by Malvern analyzer. FTIR spectra were recorded using a Vector 22, Bruker, Germany.

\subsection{Antioxidant properties of Zinc oxide nanoparticles using DPPH assays}

With small modifications, the procedure was carried out according to Bhakya et al. (2016) [40]. The scavenging properties of flower extract, ZnO NPs, conventional ascorbic acid was measured using the stable radical DPPH. $1 \mathrm{ml}$ samples at various doses $(25-100 \mu \mathrm{g} / \mathrm{ml})$ were vortexed extensively with $1 \mathrm{ml}$ newly produced DPPH (1 mM in methanol). The solution was then placed at dark place for 30 minutes at $37^{\circ} \mathrm{C}$. Single bond UV-Spec was used to measure the absorbance at $517 \mathrm{~nm}$ (Systronics, AU-2701).

\subsection{Antibacterial activity}

The antagonistic properties of Zinc oxide nanoparticles, clitorea ternatea flower extract, and amikacin in opponent to MDR strains like S. aureus and E. coli were assessed by agar well diffusion method. At 
varied concentrations $(25 \mu \mathrm{g} / \mathrm{ml}$ to $100 \mu \mathrm{g} / \mathrm{ml})$, the three samples were poured in the wells on the bacterial culture plates. The samples were allowed to diffuse into the agar bacterial lawn by allowing them to sit at room temperature for 10 minutes. After a 24 -hour incubation period at $37^{\circ} \mathrm{C}$, the plates were examined. The inhibitory zone was measured in millimeters [41].

\subsection{Biofilm Inhibition Assay}

Twenty four hour matured bacterial using a tissue culture plate technique, the ability of ZnO NPs at various concentrations $(25 \mu \mathrm{g} / \mathrm{ml}$ to $100 \mu \mathrm{g} / \mathrm{ml})$ to prevent the creation of bacterial biofilms was investigated. One $\mathrm{cm}^{2}$ cover slides Seeded into the culture plates with $10 \mathrm{~mL}$ Luria bertani broth (TSB) containing $1 \%$ glucose produced the test organisms. After 24 hours incubation, planktonic cells washed away from cover slip by $\mathrm{DH}_{2} \mathrm{O}$, then add 0.2 percent crystal violet stain on glass slides. Phase Contrast microscope was used to monitor the growth of biofilms at a magnification of X40. On the other hand, percentage of biofilm inhibition was quantified by micro-ELISA auto reader with $570 \mathrm{~nm}$. The conventional approach of Stepanovic et al.2007 was used to finish the elucidation of biofilm growth [42].

$$
\text { \%ofbiofilminhibition }=\frac{1-\text { OD570ofCellstreatedwithZnONPs }}{\text { OD570ofnontreatedcontrol }} \text { X100 }
$$

\subsubsection{Extraction and Quantification of EPS}

With little alteration, the procedure was carried out according to Dubois, $\mathrm{M}$ et al. the biofilm was harvested from cover slips at some point in late-log-phase by continuous agitation and centrifugation at 12000 RPM for thirty minutes with $4^{\circ} \mathrm{C}$. After centrifugation the culture supernatant was filtered and stored at cold room [43].

$$
\text { \%ofEPSinhibition }=\frac{1-\text { OD570ofCellstreatedwithZnONPs }}{\text { OD570ofnontreatedcontrol }} \text { X100 }
$$

\subsubsection{Proteolytic activity of green synthesized ZnONPs}

The proteolytic activity of $S$. aureus and E.coli cell-free supernatants cultured with and without ZnONPs at MBC concentrations was determined using the published protocol. In brief, $150 \mu \mathrm{L}$ of culture supernatants were incubated for 15 minutes at $37^{\circ} \mathrm{C}$ with $1 \mathrm{~mL}$ of 0.3 percent azocasein. After incubation samples were centrifuged and the absorbance recorded at $400 \mathrm{~nm}$ was measured [41].

$$
\text { \%ofproteolyticactivity }=\frac{1-\text { OD400ofCellstreatedwithZnONPs }}{\text { OD400ofnontreatedcontrol }} \text { X100 }
$$

\subsection{Cytotoxic Activity using MTT Assay}

The cell viability of green synthesized ZnONPs, DOX were demonstrated by MTT assay. MCF-7 Cells were injected in 96-well plate. Following cell seeding, the sample (DOX, ZnO nanoparticles) was treated with 
various doses ( 5 to $20 \mu \mathrm{g} / \mathrm{ml}$ ), and incubated for 24 hours at $37^{\circ} \mathrm{C}$. After incubation, the OD was measured at $570 \mathrm{~nm}$, and their IC50 values were also computed [44].

$$
\% \text { Cellviability }=\frac{\text { ExperimentalOD570 }}{\text { ControlOD570 }} \text { X100 }
$$

\subsubsection{Morphological assays}

In MCF-7 cells treated with ZnO NPs and DOX at various doses ( 0 , IC50, and $20 \mu \mathrm{g} / \mathrm{ml}$ ) for 24 hours, the changes in morphology were evaluated under the microscope to identify the alterations generated by $\mathrm{ZnO}$ NPs and DOX. The phase contrast inverted microscope was used to capture images of the cells at a magnification of 40x (Kozo Optics) [45].

\subsubsection{Fluorescence microscopic analysis of apoptosis}

The morphological aspects of apoptosis were studied using acridine orange and ethidium bromide (AO/EtBr) and 4',6-Diamidino-2-phenylindole dihydrochloride (DAPI) staining. The $\mathrm{IC}_{50}$ of $\mathrm{ZnO}$ NPs and DOX were exposed for 24 hours after the cells were sown in six-well plates. After treatment, the well plates were filled with $20 \mu \mathrm{l}$ of fluorescence dye. The cells were then investigated using fluorescent dyes under a fluorescence lens [45].

$$
\text { Apoptoticcells } \backslash \%=\frac{\text { Totalnumberofapoptoticcells }}{\text { Totalnumberofnormalandapoptoticcells }} \mathrm{X} 100
$$

\subsubsection{Lactate dehydrogenase (LDH) cell cytotoxicity assay.}

The LDH cell cytotoxicity assay was carried according to the method of Holder, A. L., \& Marr, L. C with little modification [46] [Holder, A. L., \& Marr, L. C. 2013]. In a 6-well plate, 2 X 105MCF-7 cells were introduced per well and cultured in a $\mathrm{CO} 2$ incubator until confluent growth was achieved. The cells were then treated with various doses of $\mathrm{ZnO}$ nanoparticles, and $\mathrm{DOX}$, then the plate was incubated at $37^{\circ} \mathrm{C}$ in a $\mathrm{CO}_{2}$ incubator for 24 hours. After incubation the OD was monitored every 15 seconds for 3 minutes at $340 \mathrm{~nm}$.

\subsubsection{ROS production assays}

The dye 2, 7-dichlorodihydrofluorescein diacetate (DCFH-DA) was used to monitor intracellular ROS production. MCF-7 cells were treated for 24 hours with various concentrations $(0, I C 50$, and $20 \mu \mathrm{g} / \mathrm{ml})$ of ZnO NPs and DOX. The cells were then examined using a fluorescence spec. [47].

\subsection{Statistical analysis}

All the data were statistically analyzed by ANOVA using Tukey's HSD test, Value was defined as a significant difference between the exposed and control groups. The findings are results were expressed as mean standard deviation of 3 trials. 


\section{Results And Discussion}

\subsection{Synthesis and characterization of ZnO NPs}

After 4 hours of incubation, the combined solution of clitoria ternatea flower extract and zinc nitrate reactant caused an apparent color shift from yellowish brown to off-white present in green synthesis protocols. The color changes indicate the ZnO NPs formation. In agreement with our results, Solanum torvum [48], and Rutagraveolens [49] phyto mediate synthesized ZnO NPs formed a white precipitate. The spectral absorbance peak of the green synthesized ZnO NPs shifted mainly at $335 \mathrm{~nm}$ (Figure-1A). The distinguishing feature of $\mathrm{ZnO} N P s$ is spectral absorbance at $335 \mathrm{~nm}$, as previously reported [50].

Figure-1B depicts the XRD patterns of green synthesized ZnO nanoparticles using clitorea ternatea flower extract. The features of crystalline peaks are shown in the diffraction pattern, which corresponds to (002), (101), (102),(110), (103) and (200) crystal planes, respectively, which is in agreement with the previously reported work [51]. The diameter of zinc oxide crystallites was calculated using the Debye-Scherrer formula, and the highest peaks at 101 planes positioned at $36.2^{\circ}$, the crystallite size is estimated to be around $52 \mathrm{~nm}[22,52,53]$. On the other hand, all the peaks were matched with the JCPDS card No. 361451 , also our results strongly in agreement with previous report [54]. Also, no other peaks with contaminants were observed, which indicates that the green synthesized powder is pure phase of $\mathrm{ZnO}$ NPs.

The composition of functional groups in green synthesized ZnO NPs is determined by FT-IR. It also suggests that phenolic chemicals, alkynes, terpenoids, and flavonoids interact to form $\mathrm{ZnO}$ nanoparticles. Figure-1C shows the FT-IR spectra of green synthesized $\mathrm{ZnO}$ nanoparticles in the $400-4000 \mathrm{~cm}^{-1}$ range. The FT-IR spectrum revealed a number of peaks present at 3455, 1640, 1400, 1070.1, 960, and $846 \mathrm{~cm}^{-1}$ (Figure-1C). The 3455 peaks correspond to $\mathrm{H}$ bonded $\mathrm{OH}$ stretch. The stretching bands of $\mathrm{C}=\mathrm{O}$ functional groups cause the 1640 peak. The amine single bon $\mathrm{d} \mathrm{NH}$ vibration stretch in protein amide linkages is represented by the peak at $1400[55,56]$. The medium spectral peak at $960 \mathrm{~cm} 1$ indicates the presence of $-\mathrm{OH}$ groups in phenols. Other brief peaks ranging from 500 to $850 \mathrm{~cm} 1$ were assigned the presence of metal-oxygen (ZnO NPs). [57, 58]. The presence of a large number of phenols was established, which could be related to the capping of clitorea ternatea flower extract components onto the resulting nanoparticles, implying that the phenols serve as reduction and capping agents.

The size and shape of clitorea ternatea flower-mediated synthesized ZnO-NPs were examined using TEM. Based on Figures-2A and B, it is possible to conclude that the particles in the synthesized sample were well-arranged, agglomerated Rod shapes with sizes ranging from $40 \mathrm{~nm}$ to $81 \mathrm{~nm}$. According to previous reports, there was a clear correlation between NP size and activity, with an increase in activity as NP size decreased [59]. Energy dispersive spectroscopy confirms the elemental structures found in the materials (EDS). As shown in Figure-2C, a trace elemental imaging of ZnO NPs by EDX pattern was obtained with zinc $70 \%$. The nanomaterial synthesis with plant extracts showed pure zinc oxide nanoparticles, according to the EDS analysis, which is in consistent with earlier findings. [60]. 
In addition, the particle size and zeta potential analyses were used to determine the hydrodynamic size and stability of green synthesized ZnO NPs. Particle size analysis is mostly used to determine the particle sizes in various nano solutions. The extent of particle aggregations in water media was measured by the mean hydro-dynamic particle diameter (d. $\mathrm{nm}$ ) [61, 62]. The measurement of particles in an electric field is used to calculate zeta potential. Furthermore, the particle's surface charge and local environment have a crucial effect in determining the zeta potential [63]. The results of our experiment revealed a particle size of $45-86 \mathrm{~nm}$, a zeta potential of $-35.5 \mathrm{mV}$, with PDI of 0.8872. (Figure-2D and E). Negative potential value supports, relatively high stability, similar study was reported by $[58,64]$.

\subsection{Antioxidant activity of ZnO NPs using DPPH assay}

The C.ternatea mediated synthesized ZnO NPs, C. ternatea flower extract and ascorbic acid were evaluated using an in vitro DPPH free radical scavenging experiment. This method is based on the reduction of the DPPH radical to the nonradical form $\mathrm{DPPH}-\mathrm{H}$ in the presence of a hydrogen-donating antioxidant. At $100 \mathrm{~g} / \mathrm{ml}$ concentration, ZnO NPs showed $94.10 \%$ greater DPPH activity flowed by ascorbic acid $78.07 \%$ and flower extract $66.1 \%$, which is shown in Figure-3 and table-1.

\subsection{Antibacterial activity of green synthesized ZnO NPs}

The antibacterial properties of green generated ZnO NPs were demonstrated using the agar well diffusion method. The bacteria S. aureus and E. coli were evaluated using varying concentrations $(25 \mu \mathrm{g} / \mathrm{ml}$ to 100 $\mu \mathrm{g} / \mathrm{ml}$ ) of $\mathrm{ZnO}$ nanoparticles and Clitorea ternatea flower extract. Table-2 displays the average values of the zone of inhibition $(\mathrm{mm})$ from three experiments. The antibacterial properties of ZnO NPs differ depending on the outer layer of bacterial cells. Chai $\mathrm{H}$. $Y$ et al. also reported similar findings. [65]. In the pathogens studied, flower extract had a relatively modest zone of inhibition. The antibacterial activity was shown to be dependent on the concentrations of ZnO NPs and flower extract. In the highest doses $(100 \mu \mathrm{g} / \mathrm{ml}), \mathrm{ZnO}$ NPS and flower extract exhibited stronger antibacterial efficacy, as shown in Table 1. ZnO NPs and flower extract showed diameters of inhibition zones (DIZs) for E. coli $21.2 \pm 0.15$ and S. aureus $17 \pm 0.21 \mathrm{~mm}$ bacteria, respectively, at $100 \mu \mathrm{g} / \mathrm{ml}$ concentration. In this work, it was revealed that green produced ZnO NPs had stronger bactericidal activity against Gram-negative bacteria (E. coli) than Gram-positive bacteria (S. aureus). This is due to the ability of ZnO NPs to penetrate the cell walls of both Gram-positive and Gram-negative bacteria [66]. Metal nanoparticles create reactive ROS that can penetrate bacterial cells and limit their growth, according to Slavin, Y. N. et al [67]. 
Table 1

In vitro antioxidant activity of green synthesized ZnO NPs, Flower extract, and Ascorbic acid by DPPH.

\begin{tabular}{|llll|}
\hline Sample & \multicolumn{2}{l}{ \% of Scavenging activity } \\
\cline { 2 - 4 } Concentration & Petals extract & Ascorbic acid & ZnO-NPs \\
\hline $25 \mu \mathrm{g} / \mathrm{ml}$ & $7.90 \pm 1.56^{\mathrm{a}}$ & $13.14 \pm 1.98^{\mathrm{a}}$ & $21.41 \pm 1.68^{\mathrm{a}}$ \\
\hline $50 \mu \mathrm{g} / \mathrm{ml}$ & $17.76 \pm 2.75^{\mathrm{b}}$ & $28.88 \pm 3.10^{\mathrm{b}}$ & $45.55 \pm 3.63^{\mathrm{b}}$ \\
\hline $75 \mu \mathrm{g} / \mathrm{ml}$ & $43.88 \pm 0.50^{\mathrm{c}}$ & $58.85 \pm 2.39^{\mathrm{c}}$ & $72.24 \pm 1.17^{\mathrm{c}}$ \\
\hline $100 \mu \mathrm{g} / \mathrm{ml}$ & $66.41 \pm 1.56^{\mathrm{d}}$ & $78.07 \pm 0.96^{\mathrm{d}}$ & $94.10 \pm 2.06^{\mathrm{d}}$ \\
\hline
\end{tabular}

The data represent the mean values of three independent experiments and are presented as mean \pm SD of the absorbance. Different letters indicated the significance differences (ANOVA followed by Tukey's HSD, $a=0.005)$

Table 2

Table displays the average values of the zone of inhibition $(\mathrm{mm})$ from three experiments.

\begin{tabular}{|llllll|}
\hline Samples & Bacteria & \multicolumn{4}{l}{ Zone of inhibition (mm) } \\
\cline { 3 - 6 } & \multicolumn{5}{c|}{ Concentration of samples } \\
\cline { 2 - 6 } & & $25 \mu \mathrm{g} / \mathrm{ml}$ & $50 \mu \mathrm{g} / \mathrm{ml}$ & $75 \mu \mathrm{g} / \mathrm{ml}$ & $100 \mu \mathrm{g} / \mathrm{ml}$ \\
\hline \multirow{2}{*}{ Flower extract } & S. aureus & $2.78 \pm 0.4^{\mathrm{a}}$ & $5.39 \pm 0.31^{\mathrm{b}}$ & $8.14 \pm 0.45^{\mathrm{c}}$ & $11.2 \pm 0.62^{\mathrm{d}}$ \\
\cline { 2 - 6 } & E. coli & $5.15 \pm 0.21^{\mathrm{a}}$ & $8.72 \pm 0.11^{\mathrm{b}}$ & $11.45 \pm 0.21^{\mathrm{c}}$ & $13.66 \pm 0.49^{\mathrm{d}}$ \\
\hline Zno NPs & S. aureus & $6.56 \pm 0.14^{\mathrm{a}}$ & $9.05 \pm 0.21^{\mathrm{b}}$ & $12.14 \pm 0.23^{\mathrm{c}}$ & $17 \pm 0.21^{\mathrm{d}}$ \\
& E. coli & $8.05 \pm 0.17^{\mathrm{a}}$ & $12.12 \pm 0.93^{\mathrm{b}}$ & $15.55 \pm 0.17^{\mathrm{c}}$ & $21.2 \pm 0.15^{\mathrm{d}}$ \\
\hline
\end{tabular}

The data represent the mean values of three independent experiments and are presented as mean \pm SD of the absorbance. Different letters indicated the significance differences (ANOVA followed by Tukey's HSD, $a=0.005$ )

\subsection{Antibiofilm properties of ZnO nanoparticles via Clitorea ternatea flower extract}

\subsubsection{Microscopic observations}

The effect of green synthesized ZnO NPs on biofilm was convincingly demonstrated in microscopic investigations. The control slides had a thick covering of biofilm, whereas the treated samples had a substantial reduction in biofilm production at their BIC $(100 \mathrm{~g} / \mathrm{ml})$, according to light microscopic 
examination. To confirm the anti-biofilm properties of zinc nanoparticles was done to validate the results obtained by light microscopy. Biofilms dispersed and were eventually replaced by single planktonic cells on the slide as the concentration of ZnO NPs increased, as seen in Figure-4A. Biofilm disintegration was triggered by ZnO NPs, which decrease the biofilm surface area and biofilm texture. These findings reveal that biofilm destruction of ZnO NPs was dose-dependent, with the best suppression shown at high doses of $100 \mu \mathrm{g} / \mathrm{ml}$ (Figure- 4B).

\subsubsection{Estimation of EPS inhibition and Proteolytic of green synthesized ZnO NPs}

Bacterial cells produced some biological substances like polymers, protein, lipids, DNA, etc, which is concerned to the production of bacterial biofilms and can help defend bacterial cells. The study of EPS synthesis in biofilm forming bacteria (E. coli and S. aureus) treated with various dosages of ZnO NPs (25$100 \mathrm{~g} / \mathrm{ml}$ ) is reported here. Green synthesized NPs significantly increasing EPS reduction on tested bacteria when compared to untreated bacterial cells (control), as shown in Figure-4C. The reduction of Exopoly saccharide (EPS) not only inhibited biofilm growth but also effectively detached existing biofilms. Furthermore, we examined into the protease inhibitory activity of ZnO NPs $(25-100 \mathrm{~g} / \mathrm{ml})$ in E. coli and found that it reduced protease production by 23-92 percent, followed by S. aureus (Figure-4D).

\subsection{Cytotoxic effect and LDH leakage of ZnO NPs on MCF- 7 cell line}

The anticancer activity of ZnO NPs and Doxorubicin in the MCF-7cell line was tested at various concentrations for $24 \mathrm{~h}$. The maximum cytotoxic level of ZnO NPs and Doxorubicin in MCF-7 cells was $16.7 \pm 0.9 \%$ and $24.01 \pm 1.22 \%$. ZnO NPs had a highest cell viability reduction against the MCF-7 cell lines compared to Doxorubicin. In addition, our result showed that MCF-7cells proliferations were notably inhibited by ZnO NPs, Doxorubicin with $\mathrm{IC}_{50}$ rate of $12.1,13.4 \mu \mathrm{g} / \mathrm{ml}$ of the concentration as shown in Figure-5A. As well as figure 4 revealed, that green synthesized zinc oxide nanoparticles and DOX have significant anticancer action towards MCF-7 cells, based on the nanoparticle dosage. On the other hand, cytotoxicity of ZnO NPs was higher than DOX, which confirm that the synthesized NPs had more potent towards MCF-7. Many researchers indicated that cell viability in $50 \%$ or higher indicate that the nanoparticle is non-cytotoxic, but cell viability in below $50 \%$ indicates that the nanoparticles are cytotoxic. Our results were strongly compared with previously accessible data that the green synthesized zinc oxide nanoparticles kill cancer cells more effectively, and the similar result was reported in previously $[68,69]$. Similarly, obtained the IC50 value of Santalum album leaf extract mediated synthesized zinc oxide nanoparticles was shown at $10 \mu \mathrm{g} / \mathrm{ml}[70]$.

$\mathrm{LDH}$ release experiment is one of the cytotoxic evaluation assays that measures cell membrane breaks and lactase de hydrogenase leakage in the testing medium, which is used to confirm the cell death. MCF7 cells were treated with different dosages of ZnO NPs and doxorubicin for 24 hours. Furthermore, the results demonstrated that LDH leakage increased in MCF-7 cells in a concentration-dependent way. Moreover, cells treated with the highest concentrations of ZnO NPs, DOX $(20 \mu \mathrm{g} / \mathrm{ml})$ released greater 
amounts of LDH release $(72.9 \pm 2.60$, and $61.8 \pm 2.25)$ than control MCF-7 cells (Figure-5B). Cells treated with $\mathrm{ZnO}$ NPs showed significantly higher LDH values in the medium than doxorubicin, which is point out that $\mathrm{ZnO}$ NPs were more potent in producing cytotoxicity in MCF-7 cells, which are summarized in Figure 4. This result confirmed that ZnO NPs may possibly produce cell death. Figure 4 shows the morphological evidence of zinc nanoparticle-treated MCF-7 cells, which shows that ZnO NPs treatment, suppressed cell growth and promoted cell crumbling in human cervical cancer cells in a dose dependent mode. Our results strongly agreement with earlier report LDH is a stable cytosolic enzyme that is released when necrotic cells' membranes are damaged [71]. LDH activity rises in the medium as a result of cell membrane breakage and enzyme leakage, and it can be used to detect cell death and membrane permeability [72].

\subsubsection{Morphological study of cancer cells treated with ZnO NPs}

After 24 hours of ZnO NPs treatment, the morphological alterations in MCF-7 cells were compared to the control cells (Figure-6A). The cells in the pre-treated groups had an uneven shape, and the treated groups had a higher number of dead cells. The cancer cells exposed with ZnO NPs had completely lost their membrane integrity and had detached from the growth plate. The cells treated with ZnO NPs and doxorubicins (IC50) were more dangerous than control cells, with a higher rate of dead cells. In MCF-7 cells treated with ZnO NPs and doxorubicin, the most noticeable morphological characteristics of apoptosis were detected by $\mathrm{AO} / \mathrm{EtBr}$ staining and colorimetric assays. Apoptosis is a multicellular organism's process of controlled cell death that results in morphological changes such as blebbing, cell shrinkage, nuclear fragmentation, chromatin condensation, and chromosomal DNA fragmentation [45]. The fluorescent DNA binding dye acridine orange/ ethylene dibromide (AO/EtBr) revealed various DNA states in alive and apoptotic cells.MCF-7 cells were treated with IC50 of ZnO NPs and doxorubicin for 24 $h$, and the results shown in Figure-6B. The percentage of cellular damage rate was $48.2 \pm 2.06$ and $42.8 \pm$ 1.15 was respectively higher than control cells.

On the other hand, DAPI staining revealed $\mathrm{IC}_{50}$ of $\mathrm{ZnO} \mathrm{NPs}$ and DOX-induced nuclear destruction. As shown in Figure-6C, MCF-7 cells treated by ZnO NPs and DOX had apoptotic nuclei (nuclear condensation or destructed chromatin), but the untreated cells had normal nuclei. The IC50 of ZnO NPs and DOX towards MCF-7 cells were recorded at $24 \mathrm{~h}$ after treatment, and nuclear condensation rate was $44.3 \pm$ 1.94and $34.5 \pm 0.88$ respectively. Analysis of nuclear morphology in MCF-7 cells, apoptotic alterations including chromatin condensation, nucleus disintegration, and the development of apoptotic bodies were observed. In recent studies reported that the Ag NPs cause DNA injury and death in cancer cells, which is consistent with our findings [73].

\subsubsection{Estimation of ROS and caspase-3 activation Levels in MCF-7 Cells:}


In the present study, intracellular ROS levels were detected by H2DCF-DA in ZnO NPs and treated MCF-7 cells. Spectro fluorimetric study also reveals that ZnO NPs therapy causes more intracellular ROS formation than free untreated cells (Figure-7A). In MCF-7 cells, IC50 of ZnO NPs and DOX produced the higher ROS (96 percent) out of tested dosage examined.

The activity of caspase-3 was examined to the potential effect of green synthesized zinc nanoparticles on the apoptotic pathway. The caspase-3 activity was measured using a colorimetric test kit. Caspases are interaction cysteine protease enzymes that are crucial role in the cell's apoptotic cascade. The higher rate of caspase-3 activation in this study revealed, that IC50 of ZnO NPs and DOX caused cell death via apoptosis. The activity of caspases was measured as a fold increase compared control samples which are plotted in Figure-7B. The expression of executor caspase -3 was significantly increased in MCF-7 cells treated with ZnO NPs and DOX compared with control cell, which confirms the induction apoptosis by ZnO NPs.

\section{Conclusion}

In summary, our findings showed that ZnO NPs were synthesized by C.ternatea plant flower extract, which act as both reducing and capping source. TEM, DLS, and Zeta investigation indicated that the synthesized ZnO NPs are rod shaped, stable with average particle size ranges of $84 \mathrm{~nm}$. XRD analysis was used to determine the crystalline nature of ZnO NPs. Further, the presence of pytochemical and their interactions on NPs was confirmed through FT-IR study. In addition, the ZnO NPs were capable of showing the antioxidant activity and antibacterial effect, biofilm inhibition against tested pathogen. Furthermore, ZnO NPs produces significant cytotoxicity on breast cancer MCF-7 cells, which was confirmed by MTT cytotoxicity and LDH release assay. Moreover, ZnO NPs induces apoptosis by increasing the ROS pattern and nuclear disintegration and DNA damage in MCF-7 cells. The green synthesized ZnO NPs inhibits the MCF-7 cells, through intrinsic apoptotic pathway. Based on these studies we propose, C. ternatea plant flower mediated synthesis of ZnO NPs are easier, quicker and ecofriendly in nature, that shows strong antioxidant, antimicrobials and anticancer activity.

\section{Declarations}

Acknowledgements: The authors would like to acknowledge financial support for this work from the Deanship of Scientific research (DSR), University of Tabuk, Tabuk, Saudi Arabia, under Grant No. S- 14410106

\section{Declaration of Competing Interest}

Authors listed in the manuscript certify that they have NO affiliations with or involvement in any organization or entity with any financial interest or non-financial interest in the subject matter or materials discussed in this manuscript. 


\section{References}

1. N. Mariappan, Recent trends in Nanotechnology applications in surgical specialties and orthopedic surgery. Biomedical and Pharmacology Journal 12(3), 1095-1127 (2019)

2. O.V. Salata, Applications of nanoparticles in biology and medicine. Journal of nanobiotechnology 2(1), 1-6 (2004)

3. K.B. Narayanan, N. Sakthivel, Coriander leaf mediated biosynthesis of gold nanoparticles. Mater. Lett. 62(30), 4588-4590 (2008)

4. P. Khandel, R.K. Yadaw, D.K. Soni, L. Kanwar, S.K. Shahi, Biogenesis of metal nanoparticles and their pharmacological applications: present status and application prospects. Journal of Nanostructure in Chemistry 8(3), 217-254 (2018)

5. M.S.S. Danish, L.L. Estrella, I.M.A. Alemaida, A. Lisin, N. Moiseev, M. Ahmadi, T. Senjyu, Photocatalytic applications of metal oxides for sustainable environmental remediation. Metals 11(1), $80(2021)$

6. M. Afifi, O.A. Almaghrabi, N.M. Kadasa (2015).Ameliorative effect of zinc oxide nanoparticles on antioxidants and sperm characteristics in streptozotocin-induced diabetic rat testes. BioMed Research International, 2015

7. R. Chandrasekaran, S. Gnanasekar, P. Seetharaman, R. Keppanan, W. Arockiaswamy, S. Sivaperumal, Formulation of Carica papaya latex-functionalized silver nanoparticles for its improved antibacterial and anticancer applications. J. Mol. Liq. 219, 232-238 (2016)

8. P. Dhandapani, A.S. Siddarth, S. Kamalasekaran, S. Maruthamuthu, G. Rajagopal, Bio-approach: ureolytic bacteria mediated synthesis of $\mathrm{ZnO}$ nanocrystals on cotton fabric and evaluation of their antibacterial properties. Carbohydrate polymers 103, 448-455 (2014)

9. H.A. Salam, R. Sivaraj, R. Venckatesh (2014). Green synthesis and characterization of zinc oxide nanoparticles from Ocimumbasilicum L. var. purpurascensBenth.-Lamiaceae leaf extract.Materials letters, $131,16-18$

10. D.K. Tripathi, P. Ahmad, S. Sharma, D.K. Chauhan, N.K. Dubey (eds.). (2017). Nanomaterials in Plants, Algae, and Microorganisms: Concepts and Controversies: Volume 1

11. G.S. Dhillon, S.K. Brar, S. Kaur, M. Verma, Green approach for nanoparticle biosynthesis by fungi: current trends and applications. Crit. Rev. Biotechnol. 32(1), 49-73 (2012)

12. P. Ramesh, A. Rajendran, M. Meenakshisundaram, Green syntheis of zinc oxide nanoparticles using flower extract cassia auriculata. J. Nanosci. Nanotechnol. 2(1), 41-45 (2014)

13. P.C. Nagajyothi, K.D. Lee (2011). Synthesis of plant-mediated silver nanoparticles using Dioscoreabatatas rhizome extract and evaluation of their antimicrobial activities.Journal of nanomaterials, 2011

14. S. Vanaraj, J. Jabastin, S. Sathiskumar, K. Preethi, Production and characterization of bio-AuNPs to induce synergistic effect against multidrug resistant bacterial biofilm. J. Cluster Sci. 28(1), 227-244 (2017) 
15. O. Dlugosz, J. Chwastowski, M. Banach, Hawthorn berries extract for the green synthesis of copper and silver nanoparticles. Chem. Pap. 74(1), 239-252 (2020)

16. M.S.H. Bhuiyan, M.Y. Miah, S.C. Paul, T.D. Aka, O. Saha, M.M. Rahaman, M. Ashaduzzaman, Green synthesis of iron oxide nanoparticle using Carica papaya leaf extract: application for photocatalytic degradation of remazol yellow RR dye and antibacterial activity. Heliyon 6(8), e04603 (2020)

17. F.T. Thema, E. Manikandan, A. Gurib-Fakim, M. Maaza, Single phase Bunsenite NiO nanoparticles green synthesis by Agathosmabetulina natural extract. J. Alloys Compd. 657, 655-661 (2016)

18. T. Santhoshkumar, A.A. Rahuman, C. Jayaseelan, G. Rajakumar, S. Marimuthu, A.V. Kirthi, S.K. Kim, Green synthesis of titanium dioxide nanoparticles using Psidiumguajava extract and its antibacterial and antioxidant properties. Asian Pacific journal of tropical medicine 7(12), 968-976 (2014)

19. P. Jamdagni, P. Khatri, J.S. Rana, Green synthesis of zinc oxide nanoparticles using flower extract of Nyctanthes arbor-tristis and their antifungal activity. Journal of King Saud University-Science 30(2), 168-175 (2018)

20. 20

21. G. Sangeetha, S. Rajeshwari, R. Venckatesh, Green synthesis of zinc oxide nanoparticles by aloe barbadensis miller leaf extract: Structure and optical properties. Mater. Res. Bull. 46(12), 2560-2566 (2011)

22. A. Jayachandran, T.R. Aswathy, A.S. Nair, Green synthesis and characterization of zinc oxide nanoparticles using Cayratiapedata leaf extract. Biochemistry and Biophysics Reports 26, 100995 (2021)

23. H. Agarwal, S.V. Kumar, S. Rajeshkumar, A review on green synthesis of zinc oxide nanoparticles-An eco-friendly approach. Resource-Efficient Technologies 3(4), 406-413 (2017)

24. S. Ahmed, M. Ahmad, B.L. Swami, S. Ikram, A review on plants extract mediated synthesis of silver nanoparticles for antimicrobial applications: a green expertise. Journal of advanced research 7(1), 17-28 (2016)

25. L. Jirovetz, G. Buchbauer, M.P. Shafi, N.K. Leela, Analysis of the essential oils of the leaves, stems, rhizomes and roots of the medicinal plant Alpiniagalanga from southern India. ACTA PHARMACEUTICA-ZAGREB- 53(2), 73-82 (2003)

26. N. Bala, S. Saha, M. Chakraborty, M. Maiti, S. Das, R. Basu, P. Nandy, Green synthesis of zinc oxide nanoparticles using Hibiscus subdariffa leaf extract: effect of temperature on synthesis, antibacterial activity and anti-diabetic activity. RSC Advances 5(7), 4993-5003 (2015)

27. H. Barabadi, A. Alizadeh, M. Ovais, A. Ahmadi, Z.K. Shinwari, M. Saravanan, Efficacy of green nanoparticles against cancerous and normal cell lines: a systematic review and meta-analysis. IET nanobiotechnology 12(4), 377-391 (2018)

28. V.N. Kalpana, V. Devi Rajeswari (2018). A review on green synthesis, biomedical applications, and toxicity studies of ZnO NPs. Bioinorganic chemistry and applications, 2018

29. M. Shabaani, S. Rahaiee, M. Zare, S.M. Jafari, Green synthesis of ZnO nanoparticles using loquat seed extract; Biological functions and photocatalytic degradation properties. LWT 134, 110133 
(2020)

30. N. Sisubalan, V.S. Ramkumar, A. Pugazhendhi, C. Karthikeyan, K. Indira, K. Gopinath, M.H.G. Basha, ROS-mediated cytotoxic activity of $\mathrm{ZnO}$ and $\mathrm{CeO} 2$ nanoparticles synthesized using the Rubia cordifolia L. leaf extract on MG-63 human osteosarcoma cell lines. Environ. Sci. Pollut. Res. 25(11), 10482-10492 (2018)

31. A. Hussain, M. Oves, M.F. Alajmi, I. Hussain, S. Amir, J. Ahmed, I. Ali, Biogenesis of ZnO nanoparticles using Pandanus odorifer leaf extract: anticancer and antimicrobial activities. RSC Adv. 9(27), 15357-15369 (2019)

32. S. Ahmed, S.A. Chaudhry, S. Ikram, A review on biogenic synthesis of $\mathrm{ZnO}$ nanoparticles using plant extracts and microbes: a prospect towards green chemistry. J. Photochem. Photobiol., B 166, 272284 (2017)

33. F. Bray, J. Ferlay, I. Soerjomataram, R.L. Siegel, L.A. Torre, A. Jemal, Global cancer statistics 2018: GLOBOCAN estimates of incidence and mortality worldwide for 36 cancers in 185 countries. Cancer J. Clin. 68(6), 394-424 (2018)

34. 34

35. I. Ullah, A.T. Khalil, M. Ali, J. Iqbal, W. Ali, S. Alarifi, Z.K. Shinwari (2020). Green-synthesized silver nanoparticles induced apoptotic cell death in MCF-7 breast cancer cells by generating reactive oxygen species and activating caspase 3 and 9 enzyme activities. Oxidative medicine and cellular longevity, 2020

36. A. Divya, J. Anbumalarmathi, S.A. Sharmili (2018). Phytochemical analysis, antimicrobial and antioxidant activity of Clitoriaternatea blue and white flowered leaves. Advances in Research, 1-13

37. P. Manjula, C.H. Mohan, D. Sreekanth, B. Keerthi, B.P. Devi, Phytochemical analysis of ClitoriaternateaLinn., a valuable medicinal plant. J Indian Bot Soc 92(3\&4), 173-178 (2013)

38. P.W. Citradewi, H. Hidayat, G. Purwiandono, I. Fatimah, S. Sagadevan, Clitoreaternatea-mediated silver nanoparticle-doped hydroxyapatite derived from cockle shell as antibacterial material. Chem. Phys. Lett. 769, 138412 (2021)

39. P. Rajiv, S. Rajeshwari, R. Venckatesh, Bio-Fabrication of zinc oxide nanoparticles using leaf extract of Partheniumhysterophorus $\mathrm{L}$. and its size-dependent antifungal activity against plant fungal pathogens. SpectrochimicaActa Part A: Molecular and Biomolecular Spectroscopy 112, 384-387 (2013)

40. S. Bhakya, S. Muthukrishnan, M. Sukumaran, M. Muthukumar, Biogenic synthesis of silver nanoparticles and their antioxidant and antibacterial activity. Applied Nanoscience 6(5), 755-766 (2016)

41. S. Vanaraj, B.B. Keerthana, K. Preethi, Biosynthesis, Characterization of Silver Nanoparticles Using Quercetin from Clitoriaternatea $L$ to Enhance Toxicity Against Bacterial Biofilm. J. Inorg. Organomet. Polym Mater. 27, 1412-1422 (2017b)

42. S. Stepanovic, D. Vukovic, V. Hola, G.D. Bonaventura, S. Djukic, I. Cirkovic, F. Ruzicka, Quantification of biofilm in microtiter plates: overview of testing conditions and practical recommendations for 
assessment of biofilm production by staphylococci, 115 (APMIS, 2007), pp. 891-899

43. M. Dubois, K.A. Gilles, J.K. Hamilton, P.T. Rebers, F. Smith, Colorimetric method for determination of sugars and related substances. Anal. Chem. 28, 350-356 (1956)

44. R. Vivek, R. Thangam, K. Muthuchelian, P. Gunasekaran, K. Kaveri, S. Kannan, Green biosynthesis of silver nanoparticles from Annonasquamosa leaf extract and its in vitro cytotoxic effect on MCF-7 cells. Process Biochem. 47, 2405-2410 (2012)

45. K. Murugan, D. Dinesh, K. Kavithaa, M. Paulpandi, T. Ponraj, M.S. Alsalhi, G. Benelli, Hydrothermal synthesis of titanium dioxide nanoparticles: mosquitocidal potential and anticancer activity on human breast cancer cells (MCF-7). Parasitol. Res. 115(3), 1085-1096 (2016)

46. A.L. Holder, L.C. Marr (2013). Toxicity of silver nanoparticles at the air-liquid interface. BioMed research international, 2013

47. S.S. Kumar, P. Venkateswarlu, V.R. Rao, G.N. Rao, Synthesis, characterization and optical properties of zinc oxide nanoparticles. International Nano Letters 3(1), 1-6 (2013)

48. K.M. Ezealisiji, X. Siwe-Noundou, B. Maduelosi, N. Nwachukwu, R.W.M. Krause, Green synthesis of zinc oxide nanoparticles using Solanum torvum $(\mathrm{L})$ leaf extract and evaluation of the toxicological profile of the ZnO nanoparticles-hydrogel composite in Wistar albino rats. International Nano Letters 9(2), 99-107 (2019)

49. K. Lingaraju, H.R. Naika, K. Manjunath, R.B. Basavaraj, H. Nagabhushana, G. Nagaraju, D. Suresh, Biogenic synthesis of zinc oxide nanoparticles using Rutagraveolens (L.) and their antibacterial and antioxidant activities. Applied Nanoscience 6(5), 703-710 (2016)

50. Y. Song, J. Yang, Preparation and in-vitro cytotoxicity of zinc oxide nanoparticles against osteoarthritic chondrocytes. Tropical Journal of Pharmaceutical Research 15(11), 2321-2327 (2016)

51. H. Mofid, M. SeyedSadjadi, M. Hossaini Sadr, A. Banaei, N. Farhadyar, Green synthesis of zinc oxide nanoparticles using Aloe Vera plant for investigation of antibacterial properties. Advances in Nanochemistry 2(1), 32-35 (2020)

52. I. Kaskow, P. Decyk, I. Sobczak, The effect of copper and silver on the properties of Au-ZnO catalyst and its activity in glycerol oxidation. Applied surface science 444, 197-207 (2018)

53. S. Faisal, H. Jan, S.A. Shah, S. Shah, A. Khan, M.T. Akbar, S. Syed, Green synthesis of zinc oxide (ZnO) nanoparticles using aqueous fruit extracts of Myristicafragrans: their characterizations and biological and environmental applications. ACS omega 6(14), 9709-9722 (2021)

54. S. Umavathi, S. Mahboob, M. Govindarajan, K.A. Al-Ghanim, Z. Ahmed, P. Virik, C. Kavitha, Green synthesis of $\mathrm{ZnO}$ nanoparticles for antimicrobial and vegetative growth applications: A novel approach for advancing efficient high quality health care to human wellbeing. Saudi Journal of Biological Sciences 28(3), 1808-1815 (2021)

55. A.M. Awwad, N.M. Salem, A.O. Abdeen, Green synthesis of silver nanoparticles using carob leaf extract and its antibacterial activity. International journal of Industrial chemistry 4(1), 1-6 (2013)

56. L. Rastogi, J. Arunachalam, Sunlight based irradiation strategy for rapid green synthesis of highly stable silver nanoparticles using aqueous garlic (Allium sativum) extract and their antibacterial 
potential. Mater. Chem. Phys. 129(1-2), 558-563 (2011)

57. D. Sharma, M.I. Sabela, S. Kanchi, P.S. Mdluli, G. Singh, T.A. Stenström, K. Bisetty, Biosynthesis of $\mathrm{ZnO}$ nanoparticles using Jacaranda mimosifolia flowers extract: synergistic antibacterial activity and molecular simulated facet specific adsorption studies. J. Photochem. Photobiol., B 162, 199207 (2016)

58. D. Bharathi, V. Bhuvaneshwari, Synthesis of zinc oxide nanoparticles (ZnO NPs) using pure bioflavonoid rutin and their biomedical applications: antibacterial, antioxidant and cytotoxic activities. Res. Chem. Intermed. 45(4), 2065-2078 (2019)

59. A.M. Abdo, A. Fouda, A.M. Eid, N.M. Fahmy, A.M. Elsayed, Khalil, A.M. A.,.\&Soliman, A. M. (2021). Green Synthesis of Zinc Oxide Nanoparticles (ZnO-NPs) by Pseudomonas aeruginosa and Their Activity against Pathogenic Microbes and Common House Mosquito, Culexpipiens. Materials, 14(22), 6983

60. S.S. Kumar, P. Venkateswarlu, V.R. Rao, G.N. Rao, Synthesis, characterization and optical properties of zinc oxide nanoparticles. International Nano Letters 3(1), 1-6 (2013)

61. H. Qiao, Z. Wei, H. Yang, L. Zhu, X. Yan, Preparation and characterization of NiO nanoparticles by anodic arc plasma method. Journal of Nanomaterials, Article ID 795928, 5 pages (2009). doi:10.1155/2009/795928

62. J. Iqbal, B.A. Abbasi, T. Mahmood, S. Kanwal, R. Ahmad, M. Ashraf, Plant-extract mediated green approach for the synthesis of ZnONPs: Characterization and evaluation of cytotoxic, antimicrobial and antioxidant potentials. J. Mol. Struct. 1189, 315-327 (2019)

63. S.K. Chaudhuri, L. Malodia, Biosynthesis of zinc oxide nanoparticles using leaf extract of Calotropis gigantea: characterization and its evaluation on tree seedling growth in nursery stage. Applied Nanoscience 7(8), 501-512 (2017)

64. A.A. Alyamani, S. Albukhaty, S. Aloufi, F.A. AlMalki, H. Al-Karagoly, G.M. Sulaiman, Green Fabrication of Zinc Oxide Nanoparticles Using Phlomis Leaf Extract: Characterization and In Vitro Evaluation of Cytotoxicity and Antibacterial Properties. Molecules 26(20), 6140 (2021)

65. H.Y. Chai, S.M. Lam, J.C. Sin, Green synthesis of magnetic Fe-doped ZnO nanoparticles via Hibiscus rosa-sinensis leaf extracts for boosted photocatalytic, antibacterial and antifungal activities. Mater. Lett. 242, 103-106 (2019)

66. A.M. Fayaz, K. Balaji, M. Girilal, R. Yadav (2010). PT, R. Kalaichelvan, Venketesan: Biogenic synthesis of silver nanoparticles and their synergistic effect with antibiotics: a study against gram-positive and gram-negative bacteria. Nanomed Nanotechnol Biol Med, 6, 103-109

67. Y.N. Slavin, J. Asnis, U.O. Häfeli, H. Bach, Metal nanoparticles: understanding the mechanisms behind antibacterial activity. Journal of nanobiotechnology 15(1), 1-20 (2017)

68. S. Ali, K.G. Sudha, G. Karunakaran, M. Kowsalya, E. Kolesnikov, M.P. Rajeshkumar, Green synthesis of stable antioxidant, anticancer and photocatalytic activity of zinc oxide nanorods from Leea asiatica leaf. J. Biotechnol. 329, 65-79 (2021) 
69. A.H. Alrajhi, N.M. Ahmed, A. Shafouri, M., \& M.A. Almessiere, Green synthesis of zinc oxide nanoparticles using salvia officials extract. Mater. Sci. Semicond. Process. 125, 105641 (2021)

70. K. Kavithaa, M. Paulpandi, T. Ponraj, K. Murugan, S. Sumathi, Induction of intrinsic apoptotic pathway in human breast cancer (MCF-7) cells through facile biosynthesized zinc oxide nanorods. Karbala International Journal of Modern Science 2(1), 46-55 (2016)

71. S. Vijayakumar, B. Malaikozhundan, K. Saravanakumar, E.F. Durán-Lara, M.H. Wang, B. Vaseeharan, Garlic clove extract assisted silver nanoparticle-Antibacterial, antibiofilm, antihelminthic, antiinflammatory, anticancer and ecotoxicity assessment. J. Photochem. Photobiol., B 198, 111558 (2019)

72. F.D.G. Muranli (2011). Assessment of apoptosis by using ethidium bromide/acridine orange fluorescence staining method in lymphocyte cell cultures. Current Opinion in Biotechnology, (22), S105

73. P. Sanpui, A. Chattopadhyay, S.S. Ghosh, Induction of apoptosis in cancer cells at low silver nanoparticle concentrations using chitosan nanocarrier. ACS Appl. Mater. Interfaces 3(2), 218-228 (2011)

\section{Figures}

\section{Figure 1}

(A) UV-visible absorption spectrum (B) XRD pattern and (C) Fourier transform infrared (FTIR) spectroscopy analysis of ZnO NPs synthesized from Clitorea ternatea flower extract

\section{Figure 2}

(A \& B) Transmission electron microscopy (HR-TEM) and (C) Energy-dispersive X-ray (EDX), (D) Zeta potential analysis and (E) Dynamic light scattering (DLS) images of ZnO NPs synthesized from C. ternatea flower extract

\section{Figure 3}


\% DPPH scavenging activity of C.ternatea flower extracts, Ascorbic acid and ZnO NPs. The data represent the mean values of three independent experiments and are presented as mean \pm SD of the absorbance. Different letters indicated the significance differences (ANOVA followed by Tukey's HSD, $a=0.005$ )

\section{Figure 4}

(A) Light Microscopic observation (x40) of E.coli, S. aureus adhesion phases on the glass surfaces with different concentration $(25,50,75,100 \mu \mathrm{g} / \mathrm{ml}$, right to left order) of ZnO NPs against control which is indicative of glass surface with uniformly distributed cells stained with crystal violet. (B) EPS inhibition activity in E.coli, S. aureus of ZnO NPs, (C) and (D) proteolytic activity in E.coli, S. aureus of ZnO NPs. The data represent the mean values of three independent experiments and are presented as mean $\pm S D$ of the absorbance. Different letters indicated the significance differences (ANOVA followed by Tukey's HSD, $a=$ 0.005).

\section{Figure 5}

(A) Cytotoxic potential of green synthesized ZnO NPs and Doxorubicin against MCF-7 cells, (B) Lactate dehydrogenase (LDH) release from MCF-7 human breast cancer cells after treatment with various concentrations of biosynthesized ZnO NPs and Doxorubicin. The data represent the mean values of three independent experiments and are presented as mean \pm SD of the absorbance. Different letters indicated the significance differences (ANOVA followed by Tukey's HSD, $a=0.005$ ).

\section{Figure 6}

(A) Bright field and fluorescence microscopy of MCF-7 cells treated with IC50 concentrations of ZnO nanoparticles and DOX. Control cells and ZnO NPs and DOX-treated cells observed using bright field microscope $(a, b, c)$. Fluorescence microscopy of AO/EtBr-stained control cells ZnO NPs and DOX-treated cells (live cells in green color, in the treated sample ( $d, e, f)$. DAPI nuclear staining of control cells and ZnO NPs, DOX -treated cells exhibited a condensed form of nuclear materials in apoptotic cells $(g, h, i) .(B, C)$ Histogram representation of the percentage of total observed apoptotic cells against the IC50 concentration of ZnO NPs and DOX formulated on selected MCF-7 cells after $24 \mathrm{~h}$. The data represent the 
mean values of three independent experiments and are presented as mean \pm SD of the absorbance. Different letters indicated the significance differences (ANOVA followed by Tukey's HSD, $a=0.005$ )

\section{Figure 7}

(A) Effects of DOX and ZnO NP exposition on ROS generation in MCF-7 cells, (B) Quantification of caspase 3 activity in MCF-7 cells exposed to $5 \mu \mathrm{g} / \mathrm{mL}, I C_{50}$ of DOX and ZnO NPs. The data represent the mean values of three independent experiments and are presented as mean \pm SD of the absorbance. Different letters indicated the significance differences (ANOVA followed by Tukey's HSD, $a=0.005$ ) 